\title{
Phenotypic and molecular characterization of pyrazinamide resistance among multidrug-resistant Mycobacterium tuberculosis isolates in Ningbo, China
}

Yang Che ${ }^{1}$, Dingyi Bo ${ }^{2}$, Xiang Lin ${ }^{1}$, Tong Chen ${ }^{1}$, Tianfeng $\mathrm{He}^{1^{*}}$ and $\mathrm{Yi} \mathrm{Lin}^{3^{*}}$

\begin{abstract}
Background: Detection of pyrazinamide (PZA) resistance in Mycobacterium tuberculosis (TB) patients is critical, especially in dealing with multidrug-resistant Mycobacterium tuberculosis (MDR-TB) case. Up to date, PZA drug susceptibility testing (DST) has not been regularly performed in China. The prevalence and molecular characteristics of PZA resistance in M.tuberculosis isolates, especially MDR-TB have not been studied in Ningbo, China. This study aimed to analyze the phenotypic and molecular characterization of PZA resistance among MDR-TB isolates in Ningbo.

Methods: A total of 110 MDR-TB isolates were collected from the TB patients who were recorded at local TB dispensaries in Ningbo. All clinical isolates were examined by drug susceptibility testing and genotyping. DNA sequencing was used to detect mutations in the pncA gene associated with PZA resistance.

Results: The prevalence of PZA resistance among MDR-TB strains in Ningbo was 59.1\%. With regard to the history and the outcome of treatments among MDR-TB cases, the percentages of re-treated MDR-TB patients in the PZAresistant group and of successful patients in PZA-susceptible group were significantly higher than the ones in the PZA-susceptible group and in the PZA-resistant group, respectively $(P=0.027, P=0.020)$. The results showed that the resistance of streptomycin ( $67.7 \%$ vs $46.7 \%, P=0.027$ ), ethambutol ( $56.9 \%$ vs $33.3 \%$, $P=0.015)$, ofloxacin $(43.1 \%$ vs $11.1 \%, P=0.000$ ), levofloxacin (43.1\% vs $11.1 \%, P=0.000$ ), pre-XDR (pre-Xtensively Drug Resistance) (38.5\% vs $15.6 \%, P=0.009$ ), were more frequently adverted among PZA-resistant isolates compared with PZA-susceptible isolates. In addition, 110 MDR-TB was composed of 87 (PZA resistant, 78.5\%) Beijing strains and 23 (PZA resistant, 21.5\%) non-Beijing strains. Fifty-four out of 65 (83.1\%) PZA-resistant MDR strains harbored a mutation located in the pncA gene and the majority (90.7\%) were point mutations. Compared with the phenotypic characterization, DNA sequencing of pncA has sensitivity and specificity of 83.1 and 95.6\%.
\end{abstract}

\footnotetext{
* Correspondence: hetf@nbcdc.org.cn; Lily.Lin@nottingham.edu.cn

${ }^{1}$ Institute of Tuberculosis Prevention and Control, Ningbo Municipal Center

for Disease Control and Prevention, Ningbo 315010, Zhejiang, China

${ }^{3}$ Center for Health Economics, Faculty of Humanities and Social Sciences,

University of Nottingham, Ningbo, Zhejiang, China

Full list of author information is available at the end of the article
}

C The Author(s). 2021 Open Access This article is licensed under a Creative Commons Attribution 4.0 International License, which permits use, sharing, adaptation, distribution and reproduction in any medium or format, as long as you give appropriate credit to the original author(s) and the source, provide a link to the Creative Commons licence, and indicate if changes were made. The images or other third party material in this article are included in the article's Creative Commons licence, unless indicated otherwise in a credit line to the material. If material is not included in the article's Creative Commons licence and your intended use is not permitted by statutory regulation or exceeds the permitted use, you will need to obtain permission directly from the copyright holder. To view a copy of this licence, visit http://creativecommons.org/licenses/by/4.0/ The Creative Commons Public Domain Dedication waiver (http://creativecommons.org/publicdomain/zero/1.0/) applies to the data made available in this article, unless otherwise stated in a credit line to the data. 
Conclusion: The mutations within pncA gene was the primary mechanism of PZA resistance among MDR-TB and DNA sequencing of pncA gene could provide a rapid detection evidence in PZA drug resistance of MDR-TB in Ningbo.

Keywords: Multidrug-resistant, Mycobacterium tuberculosis, pncA gene, Resistance

\section{Background}

Multidrug-resistant tuberculosis (MDR-TB) which is resistant to isoniazid and rifampin continues to be a great public health threat $[1,2]$. World Health Organization (WHO) reported that about 0.48 million new cases of rifampicin-resistant $\mathrm{TB}$, which $78 \%$ had multidrugresistant TB, worldwide in 2018 were reported [3]. China has been the second burden in MDR-TB in the world with 66 thousands prevalent MDR-TB cases annually [3]. One recent report based on drug-resistant TB national survey in China showed that $7.1 \%$ of new TB cases and $21 \%$ of previously treated cases were MDR-TB [4]. The estimated incidence of TB was $0.04 \%$ residents in 2019 in Ningbo and the epidemic of MDR-TB has been considered one of a serious public health concerns in China because of its treatment failure $[4,5]$.

WHO recommends a treatment regimen including pyrazinamide (PZA) as cornerstone first-line antituberculosis agent to the majority of MDR-TB patients $[6,7]$. PZA as a pro-drug becomes toxic to M.tuberculosis under acidic conditions $(\mathrm{PH}=5.5)$ requires conversion into its active form pyrazinoic acid with the enzyme pyrazinamidase, which was encoded by the pncA gene $[8,9]$. The main genetic mechanism of pyrazinamide resistance lies in the mutations within the 561-nucleotide $p n c \mathrm{~A}$ gene $[10,11]$. Because of its uniquely bactericidal effect, detection of PZA resistance in TB patients is critical, especially in dealing with MDR-TB case.

Up to date, PZA drug susceptibility testing (DST) has not been regularly investigated in China, thus, limited data has been updated reporting PZA resistance among MDR-TB isolates in the mainland of China $[12,13]$. The prevalence and molecular characteristics of PZA resistance in M.tuberculosis isolates, especially MDR-TB have not been studied in Ningbo, China. The objective was to investigate the prevalence of PZA resistance among MDR-TB isolates in Ningbo and to analyze the characteristics of mutated pncA gene conferring PZA resistance.

\section{Methods}

\section{Study design}

The first study of drug-resistant TB in the entire Ningbo from 2015 to 2017 by Ningbo Center for Disease Control and Prevention (CDC). A total of 1325 participants registering and diagnosed with $\mathrm{TB}$ at local TB dispensaries, were recruited in the present study and all the medical and related information were collected by welltrained nurses in the local hospitals. The isolates collected from TB patients were cultured on Lowenstein-Jensen (L-J) medium for 4-8 weeks and the culture with growing colonies were delivered to the Ningbo Tuberculosis Control Institute for further drug susceptibility testing. New cases were defined as patients previously receiving none or less than one month of anti-TB treatment. Re-treated cases were defined as patients previously receiving more than one month of anti-TB treatment. One hundred and ten consecutive MDR-TB patients out of 1325 patients with full medical and microbiological information were assessed for study eligibility.

\section{Drug susceptibility testing}

Tests for susceptibility to four first-line anti-TB drugs and six second-line drugs were performed with the proportional method recommended by WHO [14]. The concentrations of drugs in L-J medium were as follows: isoniazid (INH), $0.2 \mu \mathrm{g} / \mathrm{mL}$; rifampicin (RIF), $40 \mu \mathrm{g} / \mathrm{mL}$; ethambutol (EMB), $2 \mu \mathrm{g} / \mathrm{mL}$; streptomycin (SM), $4 \mu \mathrm{g}$ $/ \mathrm{mL}$; ofloxacin (OFLX), $2 \mu \mathrm{g} / \mathrm{mL}$; levofloxacin (LVX), $2 \mu \mathrm{g} / \mathrm{mL}$; kanamycin (KAN), $30 \mu \mathrm{g} / \mathrm{mL}$; amikacin (AMK), $30 \mu \mathrm{g} / \mathrm{mL}$; capromycin (CAP), $40 \mu \mathrm{g} / \mathrm{mL}$; protionamide (PTO), $40 \mu \mathrm{g} / \mathrm{mL}$ and $\mathrm{p}$-aminosalicylic acid (PAS), $1 \mu \mathrm{g} / \mathrm{mL}$ [14]. The PZA drug susceptibility testing was performed with a Bactec MGIT 960 system and critical concentration was $100 \mu \mathrm{g} / \mathrm{mL}$ [15]. Quality control was performed during DST using the $\mathrm{H}_{37} \mathrm{RV}$ reference strains.

\section{Definitions}

\section{Drug-resistant Mycobacterium tuberculosis types}

MDR-TB was defined as those resistant to both isoniazid and rifampicin. Pre-XDR TB was defined as MDR-TB additionally resistant to either quinolone family or second-line anti-TB injectable drugs. XDR-TB was defined as MDR-TB resistant to any member of the quinolone family and at least one of the remaining second-line anti-TB injectable drugs [3].

\section{Treatment outcomes}

All patients were following the standard treatment outcomes. Standard WHO outcome definitions were used to detect MDR TB including cure, treatment completion, treatment failure, causes of death, default, and 
transferring out [16, 17]. Successful outcomes and poor outcomes were defined as cure or treatment completion failure or death, respectively. These were considered as known outcomes, whereas unknown outcomes included default, transferring, or continuing treatment.

\section{DNA extraction and sequencing}

The crude DNA was extracted from freshly harvested bacteria [18]. The cultured bacteria was extracted from the surface of L-J medium were suspended in $500 \mu \mathrm{L}$ Tris-EDTA (TE) buffer and heated in a $95^{\circ} \mathrm{C}$ water bath for $30 \mathrm{~min}$. The genomic DNA was used as template for amplification. The $p n c$ A gene was amplified with the following primers: pncA-F 5'-GTCGGTCATGTTCGCG ATCG-3' and pncA-R 5' - GCTTTGCGGGCGAGCG CTCCA-3' [19]. The $50 \mu \mathrm{L}$ PCR mixture was prepared as follows: $25 \mu \mathrm{L} 2 \times$ GoldStar MasterMix (CWBio, Beijing, China), $5 \mu \mathrm{L}$ of DNA template, and $0.2 \mu \mathrm{M}$ of each primer set. The amplifications of $p n c \mathrm{~A}$ was performed using the following conditions: 5 min of denaturation at $94{ }^{\circ} \mathrm{C}$ followed by 35 cycles (in which each cycle consisted of $94{ }^{\circ} \mathrm{C}$ for $1 \mathrm{~min}, 58^{\circ} \mathrm{C}$ for $1 \mathrm{~min}$, and $1 \mathrm{~min}$ of extension at $72{ }^{\circ} \mathrm{C}$ ) and a final extension of $72^{\circ} \mathrm{C}$ for $5 \mathrm{~min}$. PCR products were carried out at Personalbio company (Shanghai, China). Gene polymorphisms were aligned with pncA of reference strain $\mathrm{H}_{37} \mathrm{RV}$ (ATCC) using DNAstar MegAlign (version 7.1) software.

\section{Genotyping}

Members of the strains of Beijing family were identified by the RD105 multiplex PCR [20].

\section{Statistical analysis}

The percentages between PZA-resistant and PZAsusceptible MDR strains resistant to SM and others were compared and analyzed by Crosstabs and Chi square test. The sensitivity and specificity of different methods were examined by Wilson score confidence interval method. Results were considered statistically significant at a two-tailed level of 0.05 . Statistical analysis were conducted using SPSS 21.0 (SPSS., USA).

\section{Results}

\section{Demographic characteristics and drug susceptibility profiles}

Totally, $110(8.3 \%)$ out of 1325 clinical isolates were identified as MDR-TB, including $29.1 \%$ pre-XDR and 6.4\% XDR. Around 70.0\% strains were isolated from male patients (Table 1). The average age of the 110 MDR-TB patients was 46.4 years (range 19-85 years). Around $40.9 \%$ isolates were from new cases. Among 110 MDR-TB clinical isolates, 59.1, 47.3, 30.0, 30.0, 8.2, 7.3, 3.6, 1.8 and $5.5 \%$ were resistant to SM, EMB, OFLX, LVX, KAN, AMK, CAP, PTO and PAS, respectively.
With regard to the treatment history and treatment outcomes among MDR-TB cases, the percentage of retreated MDR-TB patients in the PZA-resistant group was significantly higher than those in the PZAsusceptible group $(P=0.027)$, and the percentage of treatment successful patients in PZA-susceptible group was significantly higher than in the PZA-resistant $\operatorname{group}(P=0.020)$.

The resistance phenotypic of other drugs between PZA-resistant and PZA-susceptible groups were further examined (Table 1). The resistance of streptomycin- $(P=$ $0.027)$, ethambutol- $(P=0.015)$, ofloxacin- $(P<0.001)$, levofloxacin- $(P<0.001)$ and pre-XDR- $(P=0.009)$ were more frequently detected among PZA-resistant groups compared with PZA-susceptible groups.

\section{Mutations in the pncA gene}

Totally, 50.9\% MDR-TB isolates were observed a mutation located in the pncA gene, including $91.1 \%$ of single nucleotide substitutions and $8.9 \%$ of frame-shift mutation.

Great mutant diversity in $p n c \mathrm{~A}$ gene was observed and 40 different mutant types conferred PZA resistance among MDR strains in Ningbo (Table 2). Two PZAsusceptible isolates harbored a genetic mutation in pncA gene, including 1 strains in codon 8 and 1 strains in codon 76 . Considering the phenotypic PZA susceptibility as a gold standard, detection of mutation in pncA gene exhibited a sensitivity of $83.1 \%$ and a specificity of $95.6 \%$ (Table 3).

\section{Discussion}

PZA as an important first-line anti-tuberculosis drug plays a crucial role in the therapeutic treatment of MDR-TB [21, 22]. Considering the unique effect of PZA, the detection of PZA among MDR-TB is a significant factor for initiation of PZA in the therapy regimens for these refractory patients $[23,24]$. This study showed that the PZA resistance rate among MDR-TB in Ningbo was $59.1 \%$, which higher than those in Zhejiang Province (43.1\%) [25], Shanghai (38.5\%) [26], Thailand (49.0\%) [27], United states (38.0\%) [28], and similar to a recent result from Beijing (57.7\%) [29].

About 60\% MDR patients received previous anti-TB therapy with PZA in our study, which is significantly higher than the national level (21.8\%) [4]. Our results demonstrated that the high frequency of PZA resistance may contribute to the high rate of re-treated TB patients. Therefore, we proposed to diminish the role of PZA in the treatment for MDR-TB in Ningbo. It was necessary to formulate a suitable regimen by detecting PZA resistance before using of PZA for treatment of MDR-TB cases. 
Table 1 Risk factor associate with pyrazinamide resistance among 110 MDR isolates

\begin{tabular}{|c|c|c|c|c|c|}
\hline \multirow[t]{2}{*}{ Characteristics } & \multirow[t]{2}{*}{ No.(\%) of isolates } & \multicolumn{2}{|c|}{ No.(\%) of isolates } & \multirow[t]{2}{*}{$x^{2}$} & \multirow[t]{2}{*}{$P_{\text {_value }}$} \\
\hline & & $\mathrm{PZA}^{\mathrm{R}}$ & $P Z A^{S}$ & & \\
\hline & $(n=110)$ & $(n=65)$ & $(n=45)$ & & \\
\hline \multicolumn{6}{|l|}{ Sex } \\
\hline Male & $77(70.0)$ & $41(63.1)$ & $36(80.0)$ & - & 0.057 \\
\hline Female & $33(30.0)$ & $24(36.9)$ & $9(20.0)$ & 3.626 & - \\
\hline \multicolumn{6}{|l|}{ Age group } \\
\hline$<30$ & 19 (17.3) & $9(13.9)$ & $10(22.2)$ & - & - \\
\hline $30-59$ & $61(55.4)$ & $37(56.9)$ & $24(53.3)$ & 1.047 & 0.306 \\
\hline$\geq 60$ & $30(27.3)$ & $19(29.2)$ & $11(24.5)$ & 1.211 & 0.271 \\
\hline \multicolumn{6}{|l|}{ Permanent resident } \\
\hline Yes & $58(52.7)$ & $38(58.5)$ & $20(44.5)$ & - & - \\
\hline No & $52(47.3)$ & $27(41.5)$ & $25(55.5)$ & 2.096 & 0.148 \\
\hline \multicolumn{6}{|l|}{ Treatment history } \\
\hline New case & $45(40.9)$ & $21(32.3)$ & $24(53.3)$ & - & - \\
\hline Re-treated & $65(59.1)$ & $44(67.7)$ & $21(46.7)$ & 4.863 & 0.027 \\
\hline \multicolumn{6}{|l|}{ Treatment outcome } \\
\hline Successful & $42(38.2)$ & $19(29.2)$ & $23(51.1)$ & - & - \\
\hline Poor & $68(61.8)$ & $46(70.8)$ & $22(48.9)$ & 5.393 & 0.020 \\
\hline \multicolumn{6}{|l|}{ Cavity } \\
\hline Yes & $65(59.1)$ & $39(60.0)$ & $26(57.8)$ & - & - \\
\hline No & $45(40.9)$ & $26(40.0)$ & $19(42.2)$ & 0.054 & 0.816 \\
\hline \multicolumn{6}{|l|}{ Initial sputum smear } \\
\hline Negative & $7(6.4)$ & $6(9.2)$ & $1(2.2)$ & - & - \\
\hline Positive & $103(93.6)$ & $59(90.8)$ & $44(97.8)$ & 2.192 & 0.279 \\
\hline \multicolumn{6}{|l|}{ Genotype } \\
\hline Non-Beijing family & $23(20.9)$ & $14(21.5)$ & $9(20.0)$ & - & - \\
\hline Beijing family & $87(79.1)$ & $51(78.5)$ & $36(80.0)$ & 0.038 & 0.845 \\
\hline \multicolumn{6}{|l|}{ PncA gene mutation } \\
\hline Yes & $56(50.9)$ & $54(83.1)$ & $2(4.4)$ & - & \\
\hline No & $54(49.1)$ & $11(16.9)$ & $43(95.6)$ & 65.787 & 0.000 \\
\hline \multicolumn{6}{|l|}{ Resistance to } \\
\hline SM & $65(59.1)$ & $44(67.7)$ & $21(46.7)$ & 4.863 & 0.027 \\
\hline EMB & $52(47.3)$ & $37(56.9)$ & $15(33.3)$ & 5.937 & 0.015 \\
\hline OFLX & $33(30.0)$ & $28(43.1)$ & $5(11.1)$ & 12.939 & 0.000 \\
\hline LVX & $33(30.0)$ & $28(43.1)$ & $5(11.1)$ & 12.939 & 0.000 \\
\hline KAN & $9(8.2)$ & $6(9.2)$ & $3(6.7)$ & 0.233 & 0.898 \\
\hline AMK & $8(7.3)$ & $6(9.2)$ & $2(4.4)$ & 0.903 & 0.564 \\
\hline CAP & $4(3.6)$ & $2(3.1)$ & $2(4.4)$ & 0.142 & 1.000 \\
\hline PTO & $2(1.8)$ & $1(1.5)$ & $1(2.2)$ & 0.070 & 1.000 \\
\hline PAS & $6(5.5)$ & $1(1.5)$ & $5(11.1)$ & 4.725 & 0.081 \\
\hline Pre-XDR & $32(29.1)$ & $25(38.5)$ & $7(15.6)$ & 6.764 & 0.009 \\
\hline XDR & $7(6.4)$ & $6(9.2)$ & $1(2.2)$ & 1.174 & 0.279 \\
\hline
\end{tabular}

Abbreviations: R, resistant; S susceptible; SM, streptomycin; EMB, ethambutol; OFX, ofloxacin; LFX, levofloxacin; KAN, kanamycin; AMK, amikacin; CAP, capreomycin; PTO, protionamide; PAS, para-amino salicylic acid; Pre-XDR, pre-extensively extensive drug resistance; XDR, extensive drug resistance 
Table 2 Mutations of PncA gene among MDR-TB isolates

\begin{tabular}{|c|c|c|c|c|c|c|}
\hline Nucleotide position & Codon Change & A.A change & Mutation Type & TBDReaMDB & GMTV Database & No. of isolates \\
\hline $\mathrm{T} 14>\mathrm{G}$ & 5. ATC/AGC & ILE5SER & Non-synonymous & Unreported & Unreported & 2 \\
\hline $\mathrm{T} 17>\mathrm{C}$ & 6. ATC/ACC & ILE6THR & Non-synonymous & Unreported & Reported & 2 \\
\hline G19 > T & 7.GTC/TTC & VAL7PHE & Non-synonymous & Reported & Reported & 1 \\
\hline $\mathrm{T} 20>\mathrm{G}$ & GTC/TGC & VAL7 GLY & Non-synonymous & Reported & Reported & 3 \\
\hline$A 23>G$ & 8. GAC/GGC & ASP8GLY & Non-synonymous & Reported & Reported & 1 \\
\hline$A 29>C$ & 10. CAG/CCG & GLN10PRO & Non-synonymous & Reported & Reported & 2 \\
\hline$A 35>C$ & 12. GAC/GCC & ASP12ALA & Non-synonymous & Reported & Reported & 1 \\
\hline $\mathrm{T} 40>\mathrm{G}$ & 14. TGC/GGC & CYS14GLY & Non-synonymous & Unreported & Unreported & 1 \\
\hline $\mathrm{T} 56>\mathrm{G}$ & 19.CTG/CGG & LEU19ARG & Non-synonymous & Reported & Unreported & 1 \\
\hline $\mathrm{G} 71>\mathrm{A}$ & 24. GGC/GAC & GLY24ASP & Non-synonymous & Unreported & Reported & 1 \\
\hline $\mathrm{T} 100>\mathrm{G}$ & 34. TAC/GAC & TYR34/ASP & Non-synonymous & Unreported & Unreported & 1 \\
\hline$A 139>G$ & 47. ACC/GCC & THR47ALA & Non-synonymous & Reported & Reported & 1 \\
\hline $\mathrm{A} 142>\mathrm{G}$ & 48. AAG/GAC & LYS48GLU & Non-synonymous & Reported & Reported & 1 \\
\hline $\mathrm{C} 151>\mathrm{T}$ & 51. $C A C / T A C$ & HIS51TYR & Non-synonymous & Reported & Reported & 2 \\
\hline$A 170>C$ & 57. $C A C / C C C$ & HIS57PRO & Non-synonymous & Reported & Unreported & 1 \\
\hline C184>A & 62. CCG/ACG & PRO62THR & Non-synonymous & reported & Unreported & 1 \\
\hline$C 206>$ G & 69. CCA/CGA & PRO69ARG & Non-synonymous & Unreported & Unreported & 1 \\
\hline$A 226>C$ & 76. АСТ/CСТ & THR76PRO & Non-synonymous & Reported & Reported & 1 \\
\hline$A 287>C$ & 96. AAG/ACG & LYS96/THR & Non-synonymous & Reported & Reported & 1 \\
\hline 294-95 & Deletion $T$ & FRAMSHIPT & FRAMSHIPT & Unreported & Unreported & 1 \\
\hline$C 312>A$ & 104. AGC/AGA & SER104ARG & Non-synonymous & Reported & Reported & 1 \\
\hline $\mathrm{G} 314>\mathrm{A}$ & 105. GGC/GAC & GLY105ASP & Non-synonymous & Reported & Reported & 1 \\
\hline$A 329>G$ & 110. GAC/GGC & ASP110GLY & Non-synonymous & reported & Unreported & 1 \\
\hline A345 >C & 115. CCA/CCC & PRO115PRO & Synonymous & Unreported & Unreported & 1 \\
\hline $\mathrm{T} 347>$ G & 116. CTG/CGG & LEU116ARG & Non-synonymous & Reported & Reported & 1 \\
\hline C $372>A$ & 124. GGC/GGA & GLY124GLY & Synonymous & Unreported & Unreported & 1 \\
\hline $\mathrm{T} 374>\mathrm{G}$ & 125. GTC/GGC & VAL125GLY & Non-synonymous & Reported & Reported & 1 \\
\hline 392-93 & Insertion GG & FRAMSHIPT & FRAMSHIPT & Unreported & Unreported & 3 \\
\hline G394 > T & 132. GGT/TGT & GLY132CYS & Non-synonymous & reported & Unreported & 1 \\
\hline $\mathrm{C} 401>\mathrm{T}$ & 134. GCC/GTC & ALA134VAL & Non-synonymous & Reported & Reported & 1 \\
\hline$A 403>C$ & 135. ACC/CCC & THR135PRO & Non-synonymous & Reported & Reported & 1 \\
\hline$A 407>C$ & 136. GAT/GCT & ASP136ALA & Non-synonymous & Unreported & Reported & 2 \\
\hline$A 410>C$ & 137. CAT/CCT & HIS137PRO & Non-synonymous & Unreported & Unreported & 3 \\
\hline G415 >C & 139. GTG/CTG & VAL139LEU & Non-synonymous & reported & Unreported & 1 \\
\hline $\mathrm{T} 416>\mathrm{G}$ & 139. GTG/GGG & VAL139ALA & Non-synonymous & Reported & Reported & 2 \\
\hline $\mathrm{A} 424>\mathrm{G}$ & 142. ACG/GCG & THR142ALA & Non-synonymous & reported & Unreported & 3 \\
\hline $\mathrm{T} 464>\mathrm{G}$ & 155. GTG/GGG & VAL155GLY & Non-synonymous & Reported & Reported & 1 \\
\hline $\mathrm{T} 470>\mathrm{G}$ & 157. GTG/GGG & VAL157GLY & Non-synonymous & Unreported & Unreported & 1 \\
\hline $\mathrm{A} 478>\mathrm{C}$ & 160. ACA/CCA & THR160PRO & Non-synonymous & Unreported & Reported & 2 \\
\hline 497-98 & Insertion G & FRAMSHIPT & FRAMSHIPT & Unreported & Unreported & 1 \\
\hline $\mathrm{G} 538>\mathrm{T}$ & 180. GTC/TTC & VAL180PHE & Non-synonymous & Reported & Unreported & 2 \\
\hline
\end{tabular}

Abbreviations: MDR, multi drug resistance; TBDReaMDB, Tuberculosis Drug Resistance Mutation Database; GMTV, Genome-wide Mycobacterium tuberculosis variation 
Table 3 Performance of PncA mutations for predicting PZA susceptibility

\begin{tabular}{|c|c|c|c|c|c|c|c|}
\hline \multirow{2}{*}{$\begin{array}{l}\text { Mutation } \\
\text { in PncA }\end{array}$} & \multicolumn{2}{|c|}{ PZA susceptibility ${ }^{a}$} & \multirow[t]{2}{*}{ Total } & \multirow{2}{*}{$\begin{array}{l}\text { Sensitivity } \\
\text { (95\% Cl, \%) }\end{array}$} & \multirow{2}{*}{$\begin{array}{l}\text { Specificity } \\
(95 \% \mathrm{Cl} \% \%)\end{array}$} & \multirow{2}{*}{$\begin{array}{l}\text { PPV } \\
(95 \% \mathrm{Cl}, \%)\end{array}$} & \multirow{2}{*}{$\begin{array}{l}\text { NPV } \\
(95 \% \mathrm{Cl}, \%)\end{array}$} \\
\hline & $\bar{R}$ & $S$ & & & & & \\
\hline Yes & 54 & 2 & 56 & 83.1 & 95.6 & 96.43 & 79.6 \\
\hline No & 11 & 43 & 54 & $(71.3-90.9)$ & $(83.6-99.2)$ & $(86.6-99.4)$ & $(66.1-88.9)$ \\
\hline Total & 65 & 45 & 110 & & & & \\
\hline
\end{tabular}

${ }^{\mathrm{a}} R$, resistant, $S$ susceptible, $P P V$ positive predictive value, $N P V$ negative predictive value, $C l$ confidence interval

${ }^{b}$ The sensitivity and specificity were examined by Wilson score confidence interval method

Bacterial species induces the production of oxygen radicals which result in high frequency mutagenesis by exposing to antimicrobial agents, including RIF, FQ and the aminoglycosides [30, 31]. A recent report from Alame-Emane and colleagues reveled that PZA resistance in M.tuberculosis arised after RIF and fluoroquinolone (FQ) resistance [32]. In line with our findings, one recent result from our observation was that there were high correlation between PZA resistance and several other drugs resistance, including SM, EMB, OFLX and LVX. Regarding long duration of anti-TB treatment, MDR bacteria existed more genetic mutations which may be responsible for the potential cross resistance between PZA and other drugs in our study. It is necessary to perform PZA susceptibility testing for proper management of MDR-TB with regimen containing PZA. However, traditional PZA drug susceptibility testing is not routinely performed due to the requirement of harshly acidic environment which many isolates of $M$.tuberculosis failed to grow [33]. As an alternative testing to predict the PZA susceptibility in M.tuberculosis, Molecular method based on detecting the mutation in pncA is essential [34, 35].

Previous study showed that genetic mutations constituted the most import mechanism conferring drug resistance in M.tuberculosis [36]. The result from our study suggested that genetic alternations in pncA confer 83.1\% of PZA resistance among MDR-TB in Ningbo. Previous studies demonstrated a diverse prevalence of pncA mutation among PZA resistance isolates in different regions, ranging from $45.7 \%$ in Brazil [37], $70.6 \%$ in Iran [38], 75.0\% in Thailand [27], 78.0\% in Zhejiang [25], 84.6\% in Southern China [39], and $94.1 \%$ in Sweden [40]. Additionally, pncA mutations exhibited great diversity in our study, although $p n c$ A mutations were not statistically significant between 2 genotypes - Beijing family and non-Beijing family. Hence, DNA sequencing of the entire pncA was more effective for detection of PZA resistance rather than the routine methods by covering the mutant hot-sports. Moreover, other reports suggested that many MDR-TB and XDR-TB outbreaks were caused by strains of the Beijing family which had an increased tendency to develop drug resistance [41, 42]. However, the data from our study showed that there was no significant difference between PZA-resistant and
PZA-susceptible group in genotype. The genetic background capable of accumulating resistance was not observed in our study. The effect of PZA resistance during chemotherapy on treatment outcomes are still lack of evidence [43, 44]. Our subjects were compared with successful and poor treatment outcomes in terms of resistance to PZA in this study. According to our observations, treatment outcomes were significantly better with PZA susceptible MDR patients, suggest the need for PZA resistance test to optimize treatment.

To our knowledge, this study was the first investigation on phenotypic and molecular characterization of PZA resistance among multidrug-resistant Mycobacterium tuberculosis (MDR-TB) isolates in Ningbo. Nonetheless, some limitations of this study need to be considered. First, the small sample size cannot be representative for TB patients in the whole Ningbo. Second, only MDR-TB isolates were detected in our study. Therefore, further experiments need to be analyzed the contributions of pncA mutations to PZA resistance in non-MDR isolates. However, this study provides critical evidence to diagnose PZA resistance and help guide the treatment with PZA for MDR-TB patients in this region with high MDR-TB burden.

\section{Conclusion}

The sequencing of the pncA gene in our study provided rapid and reliable information against PZA susceptibility for MDR-TB isolates in Ningbo. The PZA-resistant isolates in MDR-TB were likely to have concomitant resistance to streptomycin, ethambutol, ofloxacin, levofloxacin and pre-XDR. DNA sequencing of the entire $p n c \mathrm{~A}$ was more effective to predict PZA resistance rather than the routine methods by covering the mutant hotspots because of its high degree of diversity in pncA gene. The high prevalence of PZA resistance among MDR suggested that we should adjust PZA in a timely and accurate manner in a treatment regimen for MDRTB in this setting with TB burden. Future study should aim to clarify the potential contributions of other gene mutations to PZA resistance caused by various medication treatments.

\section{Abbreviations}

TB: Tuberculosis; WHO: World Health Organization; MDR: Multidrug-Resistant; SM: Streptomycin; EMB: Ethambutol; OFX: Ofloxacin; LFX: Levofloxacin; 
KAN: Kanamycin; AMK: Amikacin; CAP: Capreomycin; PTO: Protionamide PAS: Paza-aminosalioylate; Pre-XDR: Pre-extensively extensive drug resistance; XDR: Extensive drug resistance

\section{Acknowledgements}

We sincerely thank all the participants in this project.

\section{Authors' contributions}

YC participated in the design of the study, performed the analysis and interpretation of the data, drafted and revised the manuscript. DB, XL and TC participated in the analysis and interpretation of the data. $\mathrm{TH}$ and $\mathrm{YL}$ participated in the collection of data, revised the manuscript. All authors read and approved the final version of the manuscript.

\section{Funding}

This research was supported by Natural Science Foundation of Ningbo (grant:2019A610385) and Ningbo Health Branding Subject Fund (PPXK201810). The funder had no role in study design, data collection, analysis, interpretation of data and writing the manuscript.

\section{Availability of data and materials}

Please contact the corresponding author for data requests.

\section{Declarations}

\section{Ethics approval and consent to participate}

The study was approved by the Research Ethics Committee of Ningbo Municipal Center for Disease Prevention and Control, China. All the participants read and signed the informed consent forms. All methods were carried out in accordance with relevant guidelines and regulations.

\section{Consent for publication}

Not applicable.

\section{Competing interests}

The authors declare that they have no competing interests.

\section{Author details}

IInstitute of Tuberculosis Prevention and Control, Ningbo Municipal Center for Disease Control and Prevention, Ningbo 315010, Zhejiang, China. ${ }^{2}$ Institute of Tuberculosis Prevention and Control, Haishu Municipal Center for Disease Control and Prevention, Ningbo, Zhejiang, China. ${ }^{3}$ Center for Health Economics, Faculty of Humanities and Social Sciences, University of Nottingham, Ningbo, Zhejiang, China.

\section{Received: 25 March 2021 Accepted: 7 June 2021}

Published online: 25 June 2021

\section{References}

1. WHO, Global tuberculosis report 2020. 2020.

2. Gandhi NR, Nunn P, Dheda K, Schaaf HS, Zignol M, van Soolingen D, et al. Multidrug-resistant and extensively drug-resistant tuberculosis: a threat to global control of tuberculosis. Lancet. 2010;375(9728):1830-43. https://doi. org/10.1016/S0140-6736(10)60410-2.

3. WHO, Global Tuberculosis Report 2019. 2019

4. Zhao Y, Xu S, Wang L, Chin DP, Wang S, Jiang G, et al. National survey of drug-resistant tuberculosis in China. N Engl J Med. 2012;366(23):2161-70. https://doi.org/10.1056/NEJMoa1108789.

5. Orenstein EW, Basu S, Shah NS, Andrews JR, Friedland GH, Moll AP, et al. Treatment outcomes among patients with multidrug-resistant tuberculosis: systematic review and meta-analysis. Lancet Infect Dis. 2009;9(3):153-61. https://doi.org/10.1016/S1473-3099(09)70041-6.

6. Anthony RM, den Hertog A, Mansjo M, Werngren. New insights into the mechanisms of action of Pyrazinamide, implication for susceptibility testing, and future regimen. Int J Mycobacteriol. 2016;(suppl 1):s71-2.

7. Zumla Al, Gillespie SH, Hoelscher M, Philips PPJ, Cole ST, Abubakar I, et al. New antituberculosis drugs, regimens, and adjunct therapies: needs, advances, and future prospects. Lancet Infect Dis. 2014;14(4):327-40. https:// doi.org/10.1016/S1473-3099(13)70328-1.

8. Yadon AN, Maharaj K, Adamson JH, Lai YP, Sacchettini JC, loerger TR, et al. A comprehensive of characterization of pncA polymorphisms that confer resistance to pyrazinamide. Nat Commun. 2017;8(1):588. https://doi.org/10.1 038/s41467-017-00721-2.

9. Rahman A, Ferdous SS, Ahmed S, Rahman SMM, Uddin MKM, Pholwat S, et al. Pyrazinamide susceptibility and pncA mutation profiles of Mycobacterium tuberculosis among multidrug-resistant tuberculosis patients in Bangladesh. Antimicrob Agents Chemother. 2017;61(9):e00511-7.

10. Sheen P, Requena D, Gushiken E, Gilman RH, Antiparra R, Lucero B, et al. A multiple genome analysis of Mycobacterium tuberculosis reveals specific novel genes and mutations associated with pyrazinamide resistance. BMC Genomics. 2017;18(1):769. https://doi.org/10.1186/s12864-017-4146-Z.

11. Senqstake S, Berqval IL, Schuitema AR, de Beer JL, Phelan J, Zwaan RD, et al. Pyrazinamide resistance-conferring mutations in pncA and the transmission of multidrug-resistant TB in Georgia. BMC Infect Dis. 2017;17(1):491. https:// doi.org/10.1186/s12879-017-2594-3.

12. Li D, Hu Y, Wernqren J, Mansjo M, Zheng XB, Drobniewski F, et al. Multicenter study of the emergence and genetic characteristics of pyrazinamide-resistant tuberculosis in China. Antimicrob Agents Chemother. 2016;60(9):5159-66. https://doi.org/10.1128/AAC.02687-15.

13. Hu Y, Wu X, Luo J, Fu Y, Zhao L, Ma Y, et al. Detection of pyrazinamide resistance of Mycobacterium tuberculosis using nicotinamide as a surrogate. Clin Microbiol Infect. 2017;23(11):835-8. https://doi.org/10.1016/j.cmi.2017.03.028.

14. WHO.2008.Policy guidance on TB drug susceptibility testing (DST) of second-line drugs. WHO/HTM/TB/2008392. WHO, Geneva, Switzerland.

15. Ramirez-Busby SM, Valafar F. Systematic review of mutations in pyrazinamide associated with pyrazinamide resistance in mycobacterium tuberculosis clinical isolates. Antimicrob Agents Chemother. 2015;59(9): 5267-77. https://doi.org/10.1128/AAC.00204-15.

16. Laserson KF, Thorpe LE, Leimane V, Weyer K, Mitnick CD, Riekstina V, et al. Speaking the same language: treatment outcomes definitions for multidrug-resistant tuberculosis. Int J Tuberc Lung Dis. 2005;9(6):640-5.

17. WHO. Guidelines for the programmatic management of drug-resistant tuberculosis: emergency update 2008. Geneva: World Health Organization; 2008.

18. Zhang Z, Lu J, Wang Y, Zhao Y. Prevalence and molecular characterization of fluoroquinolone-resistant mycobacterium tuberculosis isolates in China. Antimicrob Agents Chemother. 2014;58(1):364-9. https://doi.org/10.1128/AA C.01228-13.

19. Pang $Y$, Wang $Z$, Zheng $H$, Song $Y$, Wang $Y$, Zhao $Y$. Pyrazinamide resistance determined by liquid culture at low PH better correlates with genetic mutations in MDR tuberculosis isolates. J Microbiol Methods. 2015;119:1424. https://doi.org/10.1016/j.mimet.2015.10.014.

20. Chen J, Tsolaki AG, Shen X, Jiang X, Mei J, Gao Q. Deletion-targeted multiplex PCR (DTM-PCR) for identification of Beijing/W genotypes of Mycobacterium tuberculosis. Tuberculosis (Edinb). 2007:87:446-9.

21. Budzik JM, Jarlsberg LG, Higashi J, Grinsdale J, Hopewell PC, Maeda MK, et al. Pyrazinamide resistance, mycobacterium tuberculosis lineage and treatment outcomes in San Francisco, California. PLoS One. 2014;9(4): e95645. https://doi.org/10.1371/journal.pone.0095645.

22. Miotto P, Tessema B, Taqliani E, Chindelevitch L, Starks AM, Emerson C, et al. A standardised method for interpreting the association between mutations and phenotypic drug resistance in Mycobacterium tuberculosis. Eur Respir J. 2017;50(6):1701354.

23. Huy NQ, Lucie C, Hoa TTT, Hung NV, Lan NTN, Son NT, et al. Molecular analysis of pyrazinamide resistance in Mycobacterium tuberculosis in Vietnam highlights the high rate of pyrazinamide resistance-associated mutations in clinical isolates. Emerg Microbes Infect. 2017;6(10):e86. https://doi.org/10.103 8/emi.2017.73.

24. Miotto P, Cabibbe AM, Feuerriegel S, Casali N, Drobniewski F, Rodionova Y, et al. Mycobacterium tuberculosis Pyrazinamide resistance determinants: a multicenter study. MBio. 2014;5(5):e01819-4.

25. Xia Q, Zhao LL, Li F, Fan YM, Chen YY, Wu BB, et al. Phenotypic and genotypic characterization of pyrazinamide resistance among multidrugresistant mycobacterium tuberculosis isolates in Zhejiang, China. Antimicro Agents Chemother. 2015;59(3):1690-5. https://doi.org/10.1128/AAC.04 541-14.

26. Xu P, Wu J, Yang C, Luo T, Shen X, Zhang Y, et al. Prevalence and transmission of pyrazinamide resistant Mycobacterium tuberculosis in China. Tuberculosis(Edinb). 2016;98:56-61.

27. Jonmalung J, Prammananan T, Leechawengwongs M, Chaiprasert A. Surveillance of pyrazinamide susceptibility among multidrug-resistant 
mycobacterium tuberculosis isolates from Siriraj hospital. Thailand BMC Microbiol. 2010;10(1):223. https://doi.org/10.1186/1471-2180-10-223.

28. Kurbatova EV, Cavanaugh JS, Dalton T, Click ES, Cegielski JP. Epidemiology of pyrazinamide-resistant tuberculosis in the United States, 1999-2009. Clin Infect Dis. 2013;57(8):1081-93. https://doi.org/10.1093/cid/cit452.

29. Gu Y, Yu X, Jiang G, Wang X, Ma Y, Li Y, et al. Pyrazinamide resistance among multidrug-resistant tuberculosis clinical isolates in a national referral center of China and its correlations with pncA, rpsA, and panD gene mutations. Diagn Microbiol Infect Dis. 2016;84(3):207-11. https://doi.org/10.1 016/j.diagmicrobio.2015.10.017.

30. Baharoglu Z, Mazel D. Vibrio cholerae triggers SOS and mutagenesis in responses to a wide range of antibiotics : a route towards multiresistance. Antimicrob Agents Chemother. 2011;55(5):2438-41. https://doi.org/10.1128/AAC.01549-10

31. Ysern P, Clerch B, Castano M, Gibert I, Barbe J, Liagostera M. Induction of SOS genes in Escherichia coli and mutagenesis in Salmonella typhimurium by fluoroquinolones. Mutagenesis. 1990;5(1):679-84.

32. Alame-Emane AK, Xu P, Pierre-Audigier C, Cadet-Daniel V, Shen X, Straouia $\mathrm{M}$, et al. Pyrazinamide resistance in mycobacterium tuberculosis arise after rifampicin and fluoroquinolone resistance. Int J Tuberc Lung Dis. 2015;19(6): 679-84. https://doi.org/10.5588/ijtld.14.0768.

33. Peterson ND, Rosen BC, Dillon NA, Baughn AD. Uncoupling environment $\mathrm{pH}$ and intrabacterial acdification from pyrazinamide susceptibility in Mycobacterium tuberculosis. Antimicrob Agents Chemother. 2015;59(12): 7320-6. https://doi.org/10.1128/AAC.00967-15.

34. Allana S, Shashkina E, Mathema B, Bablishvili N, Tukvadze N, Shah NS, et al. $P n c A$ gene mutations associated with pyrazinamide resistance in drugresistant tuberculosis in South Africa and Georgia. Emerg Infect Dis. 2017; 23(3):491-5. https://doi.org/10.3201/eid2303.161034.

35. Driesen M, Kondo Y, de Jonq BC, Torrea G, Asnong S, Desmaretz C, et al. Evaluation of a novel line probe assay to detect resistance to pyrazinamide, a key drug used for tuberculosis treatment. Clin Microbiol Infect. 2017;24(1): 60-4. https://doi.org/10.1016/j.cmi.2017.05.026.

36. Zhang Y, Yew WW. Mechanisms of drug resistance in Mycobacterium tuberculosis: update 2015. Int J Tuberc Lung Dis. 2015;19(11):1276-89. https://doi.org/10.5588/ijtld.15.0389.

37. Bhuju S, Fonseca Lde S, Marsico AG, de Oliveira Vieira GB, Sobral LF, Stehr $\mathrm{M}$, et al. Mycobacterium tuberculosis isolates from Rio de janeiro reveal unusually low correlation between pyrazinamide resistance and mutations in the pncA gene. Infect Genet Evol. 2013;19:1-6. https://doi.org/10.1016/j. meegid.2013.06.008.

38. Doustdar F, Khostravi AD, Farnia P. Mycobacterium tuberculosis genotypic diversity in pyrazinamide-resistant isolates of Iran. Microb Drug Resist. 2009; 15(4):251-6. https://doi.org/10.1089/mdr.2009.0066.

39. Tan Y, Hu Z, Zhang T, Cai X, Kuang H, Liu Y, et al. Role of pncA and rpsA gene sequencing in detection of pyrazinamide resistance in Mycobacterium tuberculosis isolates from southern China. J Clin Microbiol. 2014;52(1):291-7. https://doi.org/10.1128/JCM.01903-13.

40. Jureen P, Werngren J, Toro JC, Hoffner S. Pyrazinamide resistance and pncA gene mutations in Mycobacterium tuberculosis. Antimicrob Agents Chemother. 2008;52(5):1852-4. https://doi.org/10.1128/AAC.00110-08.

41. Pang Y, Zhou Y, Zhao B, Liu G, Jiang GL, Xia H, et al. Spoligotyping and drug resistance analysis of mycobacterium tuberculosis strains from national survey in China. PLoS One. 2012;7(3):e32976. https://doi.org/10.1371/journal. pone.0032976.

42. Parwati I, van Crevel R, van Soolingen D. Possible underlying mechanisms for successful emergence of the mycobacterium tuberculosis Beijing genotype strains (review). Lancet Infect Dis. 2010;10(2):103-11. https://doi. org/10.1016/S1473-3099(09)70330-5

43. Bastos ML, Hussain H, Weyer K, Garcia LG, Leimane V, Leung CC, et al. Treatment outcomes of patients with multidrug-resistant and extensively drug-resistant tuberculosis according to drug susceptibility testing to firstand second-line drugs: a individual patient date meta-analysis. Clin Infect Dis. 2014;59(10):1364-74. https://doi.org/10.1093/cid/ciu619.

44. Ceqielski JP, Kurbatova E, Vander Walt M, Brand J, Ershova J, Tupasi T, et al. Multidrug-resistant tuberculosis treatment outcomes in relation to treatment and initial versus acquired second-line drug resistance. Clin Infect Dis. 2016;62(4):418-30

\section{Publisher's Note}

Springer Nature remains neutral with regard to jurisdictional claims in published maps and institutional affiliations.

\section{Ready to submit your research? Choose BMC and benefit from}

- fast, convenient online submission

- thorough peer review by experienced researchers in your field

- rapid publication on acceptance

- support for research data, including large and complex data types

- gold Open Access which fosters wider collaboration and increased citations

- maximum visibility for your research: over $100 \mathrm{M}$ website views per year

At $\mathrm{BMC}$, research is always in progress.

Learn more biomedcentral.com/submissions 